\title{
The Vital Basis of Technology Transfer Seen from the Perspective of the SECI and BA Model: Structural Insight
}

\author{
Josef TOMAN*, Petra MAREŠOVÁ and Blanka KLÍMOVÁ
}

University of Hradec Králové, Hradec Králové, Czech Republic; josef.toman@uhk.cz; petra.maresova@uhk.cz; blanka.klimova@uhk.cz

* Corresponding author: josef.toman@uhk.cz

\begin{abstract}
The portfolio of research and technology transfer (TT) activities represents a dynamic time-limited project organizational structure. The topic of the influence of a properly organized working environment of universities and the effective creation and dissemination of knowledge in research and TT projects has been identified as a research gap. Therefore, this article focuses on the following research question: "What does the operational structure of research look like and what are its characteristics?" The main method for achieving this goal is a network analysis, the procedures of which were applied to the data of the University of Hradec Králové in the field of research and TT, specifically the data from research projects. The data file contains data of 370 research activities. The scale of the network has not been confirmed and it is also a network where the presence of the small world phenomenon has not been confirmed, which in the context of relatively high average degree of centrality indicates some redundancy in the interconnection of research teams and may be an indication of limited innovation potential of researchers of UHK teams and not fully effectively developed research basis.
\end{abstract}

Keywords: technology transfer; knowledge management; social network analysis

JEL Classification: I23; O31; O32

\section{Introduction: Knowledge Management and Technology Transfer}

Knowledge management makes it possible to explain why knowledge cannot be well transferred or communicated during the technology transfer process. The model of the relationship between knowledge management and technology transfer (TT) includes both the technology provider organization (university) and the technology recipient organization (companies between which TT takes place) work with two basic theoretical concepts environmental knowledge management and absorption capacity (Anderton \& Watson, 2018). Knowledge management enables to clarify the reasons why there are complications in the transfer or sharing of knowledge during the technology transfer process, using the concept of absorption. This concept enabled to understand how to positively influence relations between manufacturing companies and higher education organizations in order to "facilitate the process" of technology transfer. "The key factor for successful "facilitation" appears to be the examination of both subjects simultaneously by the same optics (Leonard, 1999). The absorption capacity is one of the determining abilities of a company to accept new knowledge 
and be able to benefit from it for its own innovation activities. A firm or department with a high absorption capacity has a well-developed ability to effectively transfer the knowledge it acquires from surrounding units or firms (Tsai, 2001). This is also in line with the results of related studies, which confirmed that knowledge is usually distributed unevenly within the network (Borgatti, 2003; Tsai, 2001). It is also important to emphasize that the procedural concept of absorption capacity (Lane et al., 2006) as an element indicating the abovedescribed ability to effectively receive and transmit, i.e. to further distribute the accepted properties, is directly related to the position of the organization or company (Burt, 1976), and thus makes the position of the organization one of the primary factors of success of the transfer process (Kotler et al., 2013; Tsai, 2001). In the aviation industry, we have a proven direct impact of knowledge management on a successful TT (Rafiei et al., 2016). The results of the study say that it is appropriate for managers (in this case, in the aviation industry) to pay more attention to three topics: (1) technology transfer, (2) environment preparation to facilitate a technology flow and increase performance by allocating sufficient resources and space to these activities; and (3) building and developing relationships with support organizations, research institutes and universities, which makes it possible to transfer relevant knowledge and technology in a shorter time and at a lower cost.

In this case, the first point seems interesting, which is closely related to both the sharing of experience and the transfer of formalized know-how in the form of documentation, manuals and training, which resonates with the SECI model (Nonaka, 1994). In the case of the second point, we can also find a model for Nonaka, as it can be set into the Ba model (Nonaka, 1994). Within the same model, we can identify the third point with the following types of Ba "Origin Ba" and "Dialog Ba" see Figure 3 (Nonaka, 1994). Studies on the role of universities as "open innovators" also highlight the importance of the position that the university occupies or is able to take and also defend within specific network structures (Jonsson et al., 2015; Kim et al., 2018).

There are already traditional studies on the productivity of researchers and their coauthoring cases of co-citation networks in which these researchers work, which are studies in the full sense of the word focused on the creation and sharing of knowledge in the university environment. Usually, the abilities of universities or their research teams are analyzed, such as productivity (Racherla \& Hu, 2010), openness to innovation (Powell et al., 1996; Smith et al., 2014) or the ability of companies to create new values for customers in a broader sense (Perkmann et al., 2011; Schaeffer et al., 2020; Tsai, 2001). This level, the level of creation and sharing of knowledge in the environment of universities, especially their transfer activities, is researched extensively. On the other hand, the level of creating a suitable organizational environment and learning about the processes of creating and sharing knowledge in academia is examined less often and yet according to Nonak's Ba-model, it is the level of organizational culture, which includes a key work environment for creating the so-called organizational knowledge. It turned out that the question "What does the operational structure of research look like and what are its characteristics?", i.e. what research projects are conducted and how individual knowledge from the heads of individual researchers gets into the final reports of more and more projects is not much researched, or 
at least we have not found any studies at the level of "peer-review articles" in the available Scopus or WoS databases. Therefore, we consider it appropriate to pay more attention to this issue of "creating a suitable work environment for individuals in teams performing university research". A solid starting point for studying the structure and properties of the work organization of science and research is to clarify several basic concepts from the history of universities related to the topic. The university has historically occupied some "original position" (Lee, 1998), which, as mentioned above, resulted from the tradition and activities of the university, i.e. here we usually limit ourselves to two original roles (1) Teaching and (2) Research provided in Figure 1 below.

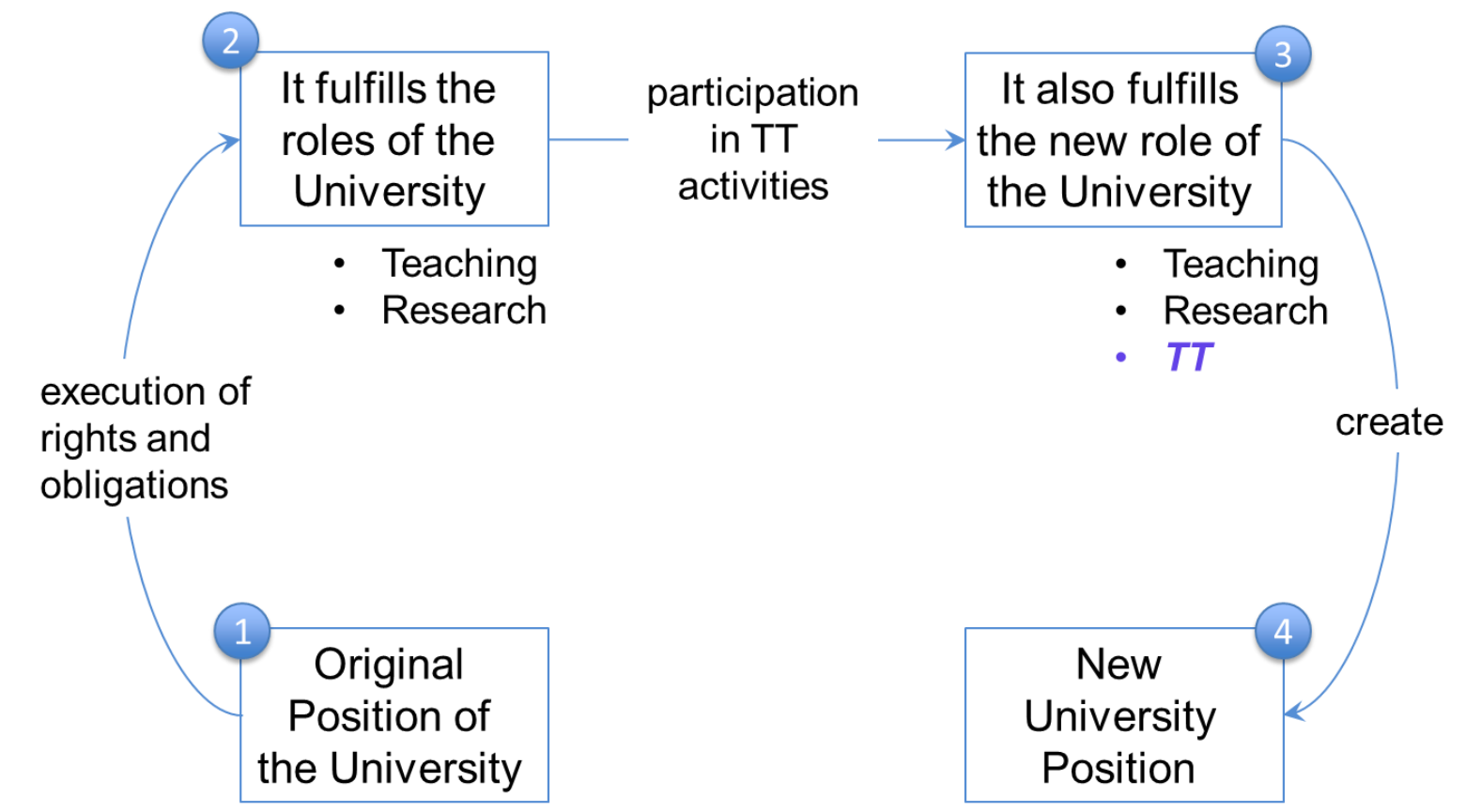

Figure 1. Conceptual scheme of the change of historical roles of the university towards TT

This defined position was then associated with "a target market" (Pritchard et al., 2016), for which the university came up with "a certain offer" (Kotler et al., 2013) that resulted from the execution of rights and obligations associated with those roles (Wasserman \& Faust, 1994). In the course of time, the university has expanded its scope to include another role (3) of TT, which is naturally linked to "new target markets" and "expansion of supply" resulting from the expanded exercise of rights and obligations associated with these roles, i.e. TT and research activities (Bozeman, 2000). Now, we will specify these two roles (TT and research activities) through research projects: Research (GAČR) and (3rd role) TT (EHP, MK-NAKI, MPO, MV-PV, MZ, MŠMT, NORWAY, TACR).

The above types of projects, together with researchers moving from project to project, create a structure that may or may not help to generate and disseminate knowledge. It is a slightly modified co-author's network, which forms a manageable structure of scientific cooperation, i.e. a portfolio of projects. To understand "What does the operational structure of research look like and what are its characteristics", we have set two successive goals: (i) to describe the time evolution of the network structure of the research project portfolio and (ii) 
identification of the so-called cut-point projects, i.e. the projects which, due to their position, eventually divide the network into two or more parts.

\section{Methods}

The main method for achieving the goal is a network analysis, the procedures of which were applied to the data of the University of Hradec Králové in the field of research and TT from the databases of UHK information systems and subsequently, their analysis, evaluation and preparation for calculations were performed. These were the data from the research projects (GAČR, TAČR). The data file contains data of 370 research activities (in the following text, the designation project may be used, but it is still the same variable, i.e. the project of R\&D activities). Within the mentioned 370 projects, 806 researchers were active in the monitored period of 2014-2019. The file contains data of 80 external entities. On average, there are about two projects per researcher and the average number of researchers per project is close to five. The first key task was how the network data will be obtained from this database, i.e. how networks will be created. The procedure for all networks created in this study was identical and followed standard networking procedures (Wasserman \& Faust, 1994).

\section{Results}

\subsection{Time Evolution of the Network Structure of the Portfolio of RED Projects}

In relation to the first sub-objective, i.e. the description of the time evolution of the network structure of the research project portfolio, Table 1 provides a summary of network metrics that characterize the six networks shown in Figure 1. Specifically, network size measured by number of nodes 19 in 2014 to 370 in 2019. These are small to medium-sized networks at an advanced stage of development. Therefore, gigantic components are already recognizable in every period. The networks show a significant share of the gigantic component in the entire network, which ranges from 47 to $85.7 \%$ of the total number of peaks.

Table 1. Structural metrics of the network of research projects from the period of 2014-2019

\begin{tabular}{lllllll}
\hline Structural metrics & $\mathbf{2 0 1 4}$ & $\mathbf{2 0 1 5}$ & $\mathbf{2 0 1 6}$ & $\mathbf{2 0 1 7}$ & $\mathbf{2 0 1 8}$ & $\mathbf{2 0 1 9}$ \\
\hline Number of network nodes & 19 & 88 & 141 & 207 & 300 & 370 \\
Number of components & 4 & 24 & 25 & 28 & 33 & 48 \\
The size of a gigantic component & 9 & 61 & 111 & 175 & 263 & 317 \\
The share of a gigantic component & 0.474 & 0.693 & 0.787 & 0.845 & 0.877 & 0.857 \\
\hline
\end{tabular}

The development of the network in the individual monitored periods is summarized in six graphs in Figure 2. The graph for the period of 2014 also shows the designations of individual projects as they are listed in the database. In subsequent periods, due to the legibility of the graph, we do not list these designations. 


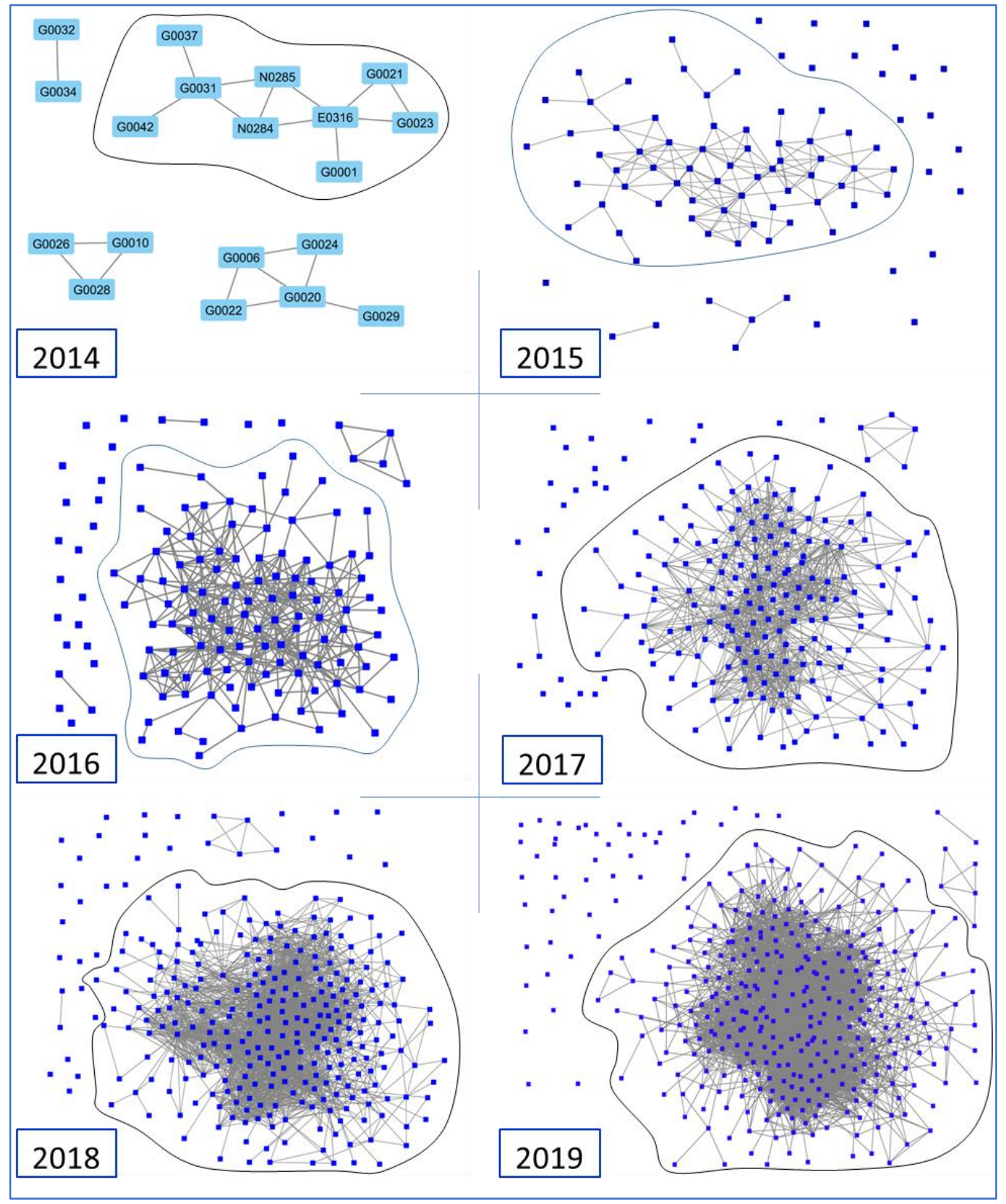

Figure 2. Time evolution of the network of research projects in the period of 2014-2019 with a marked gigantic component

For seven topological metrics see the list in the first column Table 2, the calculated values of individual topological metrics were calculated according to the relationships given in the theoretical part of this work and using routines offered by Cytoscape (Shannon, 2003) or UCINET (Borgatti, 2003). The number of researchers increased during the observed period, from 168 to 806 , i.e. almost five times (4.8 times), however, the actual values of these numbers are relatively small for deciding on the presence of the phenomenon of a small world. The necessary comparisons require order differences of the compared values (Newman, 2018). 
Table 2. Structural metrics of the research projects from the period of 2014-2019

\begin{tabular}{lllllll}
\hline Structural metrics & $\mathbf{2 0 1 4}$ & $\mathbf{2 0 1 5}$ & $\mathbf{2 0 1 6}$ & $\mathbf{2 0 1 7}$ & $\mathbf{2 0 1 8}$ & $\mathbf{2 0 1 9}$ \\
\hline Number of network nodes & 19 & 88 & 141 & 207 & 300 & 370 \\
Network density & 0.123 & 0.038 & 0.043 & 0.045 & 0.049 & 0.053 \\
Number of isolated nodes & 0 & 21 & 21 & 25 & 30 & 44 \\
Number of components & 4 & 24 & 25 & 28 & 33 & 48 \\
Network diameter & 4 & 9 & 7 & 7 & 7 & 6 \\
$\begin{array}{l}\text { Clustering coefficient } \\
\text { The average number of neighbors }\end{array}$ & 0.511 & 0.287 & 0.421 & 0.438 & 0.505 & 0.524 \\
(degree) & 2.21 & 3.34 & 5.97 & 9.31 & 14.55 & 19.57 \\
\hline
\end{tabular}

The high density (0.053) of the network indicates solid conditions for cooperation similar to the average of the network (6 steps) relative to the total number of nodes (370). In addition, the average value of the degree of centrality of 19.57 is quite high compared to the number of projects, which facilitates a certain sharing of knowledge but prevents us from declaring that it is a small world type network. From the point of view of the permeability of information and knowledge, however, the value of a high degree of centrality is a positive indicator of the possibilities of the network. The number of isolated points in the network is 44 (i.e. $>11 \%$ ). The comments were made for the final period, i.e. 2014-2019, for which the data are listed in the column labeled 2019.

Another typically monitored feature of the network is the so-called scale-free network, i.e. the presence of the so-called power law. Calculations performed in Excel based on the data obtained from the UCINET environment for the above-mentioned issues are summarized below, see Figure 3. The displayed graphs and results indicate that in none of the cases it is a scale-free network $(\alpha \notin\langle 2,3\rangle)$. The axes have a logarithmic scale.

The visualization of the network is added to the numerical analyzes, which illustrates the composition in the network of research activities in individual periods according to their type. These are project-to-project networks. The visualization of individual networks is shown in Figure 4. At first glance, without further investigation, this visualization enables to see that in all monitored periods there is a clearly predominant type of research activities at UHK represented by red.

\subsection{Identification of the Cut-point Projects}

Within the second sub-objective, i.e. the identification of projects which, due to their position, possibly divide the network into two or more parts, 21 projects that have the role of "cut-point project" for a certain part of the network were identified. We detected the highest degree value (76) in the structure of the project portfolio. With reference to the theoretical part, we know that the examined portfolio of projects can be identified with part of the Ba space (Nonaka \& Konno, 1998). A specific value of 76 means that individuals from the team that implemented the project participated in total 76 times in other projects. In other words, we can state that the bearers of knowledge who participated in the implementation of the project had a chance to spread their existing knowledge in another 76 projects. 


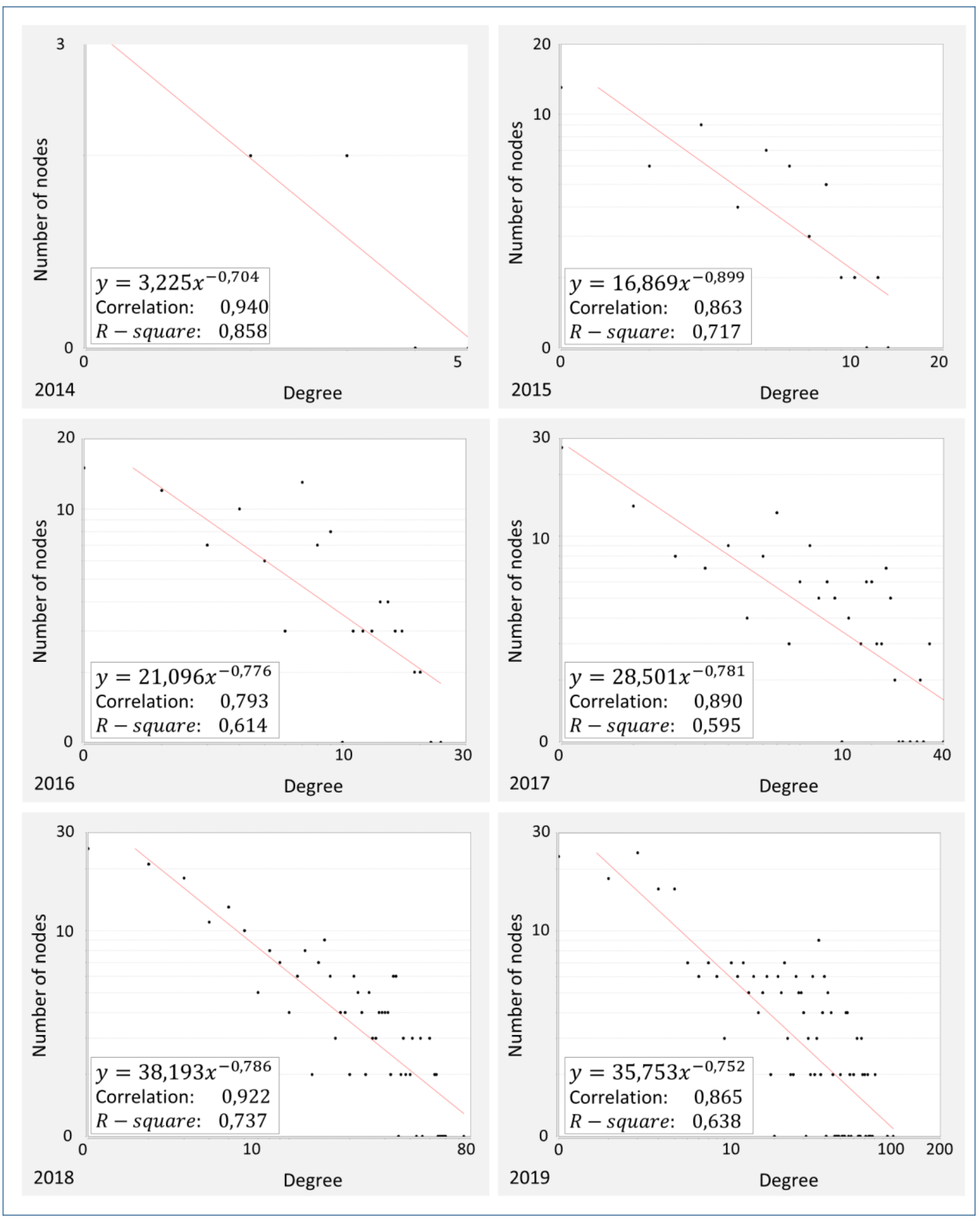

Figure 3. Probability of degree distribution for developing network between 2014 and 2019

From the point of view of developing and maintaining a network of project portfolios, the key question is how high is the risk of dividing this "path for knowledge dissemination" by the fact that for some reason a project would not occur. 


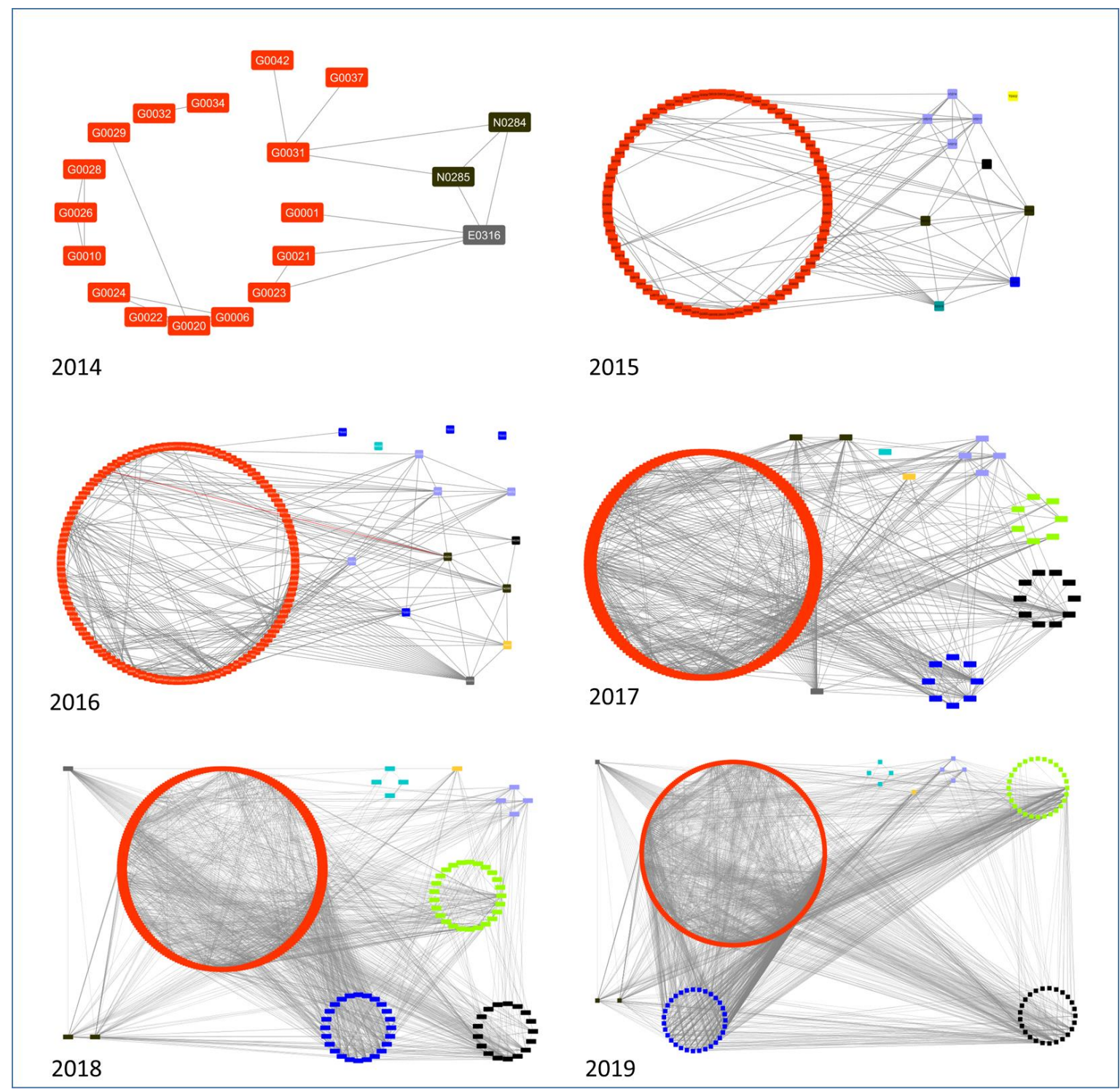

Figure 4. Development of the structure of project portfolio networks with color-coded type of projects $(\mathrm{GAČR}=$ red $)$

Figure 5 compares the situation where the four projects with the greatest cut-point potential are really removed from the network against the situation that the projects remain in the network. At the global level, this network will not be divided, as shown in Figure 5, as the remaining network of the 18 most important projects still shows multiple interconnections despite the removal of the four projects with the highest cut-point potential. However, the division of the network is already taking place at lower levels. 


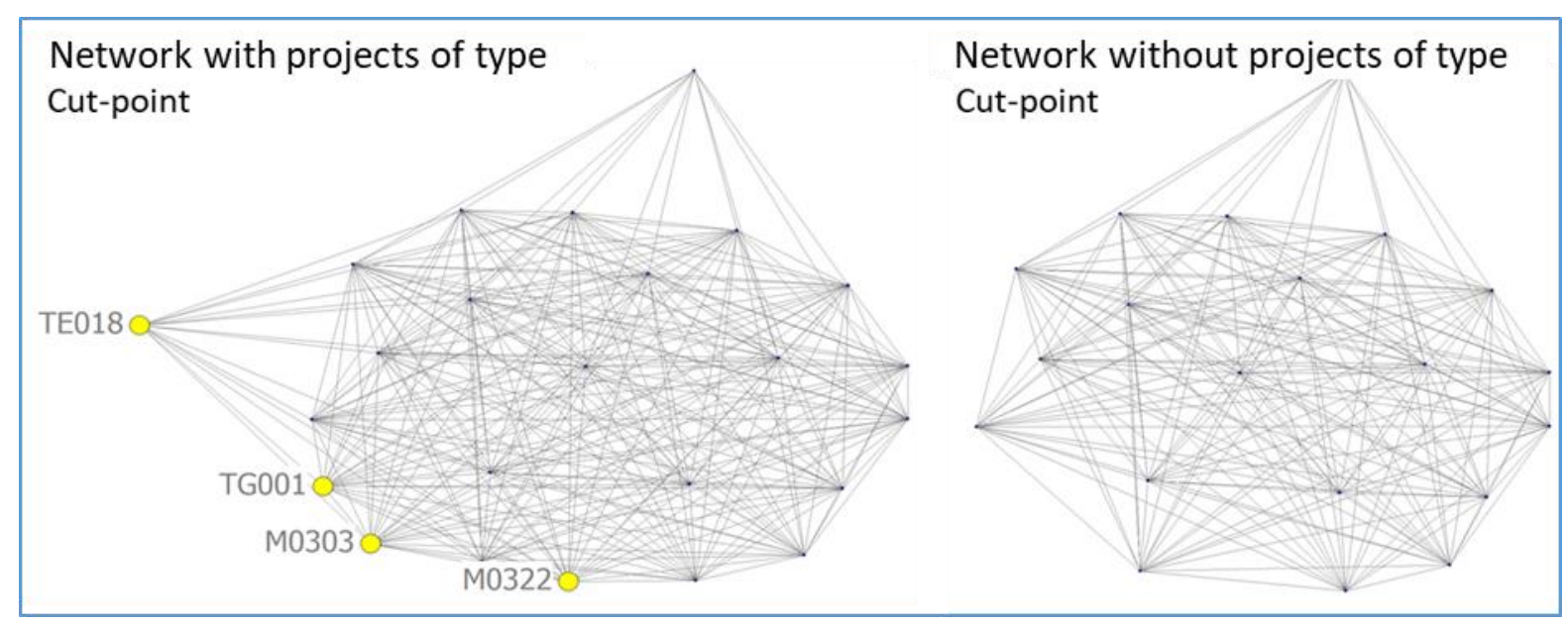

Figure 5. Results of the cut-point analysis for 2019 (filter degree> 60)

\section{Discussion}

The structure of the project network clearly demonstrated the dynamic development of the project portfolio from the original 19 projects to 370 projects. An interesting result of the analysis is essentially a linear increase in the number of components, i.e. according to the definition of interconnected parts of the network isolated from each other. In other words, the network is increasing, i.e. the number of internally interconnected cores (or individuals) which (who) are not interconnected with other clusters in the portfolio of research projects at UHK. In terms of the size of these clusters, the results indicate that the gigantic component, which determines the size of the largest cluster, covered about $53 \%$ of all projects in 2014 , while in 2019 , it was almost $85 \%$. In view of the above, the following statement will be limited to the gigantic component. With regard to the growth in the number of unconnected clusters and in accordance with the corresponding increase in the average value of the degree of centrality, the analysis indicates a growing increase in the number of projects in which an individual researcher is involved, from the original approx. $3(2.21+1)$ projects in 2014 to 20 $(19.57+1)$ in 2019 . From the performed analyzes it is not possible to confirm either the presence of the network property of small world, neither the scale-free network. From the point of view of the permeability of the network for knowledge (measured by the degree of centrality metrics), this is the axis of the network, which has increased its permeability more than nine times during the six years of its development. The results of the analysis of significant projects and cut-point projects with regard to the impersonal nature of the "project" are summarized only at the level of cut-point projects. A total of 21 projects were identified with the potential to divide the network into two or more parts. Despite the relatively high values of the centrality of these projects in the analysis, we did not identify the space for the division of the network elsewhere than at the local level, which from a university perspective with the above network heterogeneity will not be a fundamental change.

From the point of view of the intention to work with interaction with the environment and the university, the development of the number of projects and the number of projects according to the type of research activity appears to be key, i.e. GAČR, EHP, MK-NAKI, 
MPO, MV-PV, MZ. The ratio between GAČR-type projects and other projects has shifted from the original values of approx. 5:1 in favor of GAČR to 3:1 in favor of GAČR. This shift in a possible change in the perception of the university, i.e. a possible change in the position of the university, is also an important result.

\section{Conclusions}

The question of what the structure of research at UHK looks like in terms of network structure can be answered with reference to Figure 4 and Figure 5. Specific properties can be summarized as follows: (i) the fact that the scale of the network has not been confirmed indicates that the network still changes significantly with the growing number of implemented projects, (ii) it is a network where the presence of the small world phenomenon has not been confirmed, which in the context of relatively high average degree of centrality indicates some redundancy in the interconnection of research teams and may be an indication of limited innovation potential of UHK research teams and not fully effectively developed basic structure for the implementation of research projects. This might be affected by limited availability in obtaining research projects.

Acknowledgments: This work was supported by the Technology Agency the Czech Republic TL02000066 “Effective knowledge transfer management "and internal specific research "Investments under the Industry 4.0 concept."

\section{References}

Anderton, A., \& Watson, K. (2018). Knowledge Management: A Technology Transfer Perspective. SSRN Electronic Journal. https://doi.org/10.2139/ssrn.3241729

Borgatti, S. (2003). The Network Paradigm in Organizational Research: A Review and Typology. Journal of Management, 29(6), 991-1013. https://doi.org/10.1016/S0149-2063(03)00087-4

Bozeman, B. (2000). Technology transfer and public policy: a review of research and theory. Research Policy, 29(4-5), 627-655. https://doi.org/10.1016/S0048-7333(99)00093-1

Burt, R. S. (1976). Positions in Networks. Social Forces, 55(1), 93. https://doi.org/10.2307/2577097

Jonsson, L., Baraldi, E., Larsson, L.-E., Forsberg, P., \& Severinsson, K. (2015). Targeting Academic Engagement in Open Innovation: Tools, Effects and Challenges for University Management. Journal of the Knowledge Economy, 6(3), 522-550. https://doi.org/10.1007/s13132-015-0254-7

Kim, T., Park, K., \& Kim, E. (2018). Complementary or contradictory? The effects of structural holes and status on innovation. Innovation, 20(4), 393-406. https://doi.org/10.1080/14479338.2018.1478733

Kotler, P., Keller, K. L., Juppa, T., \& Machek, M. (2013). Marketing management. Grada.

Lane, P. J., Koka, B. R., \& Pathak, S. (2006). The Reification of Absorptive Capacity: A Critical Review and Rejuvenation of the Construct. Academy of Management Review, 31(4), 833-863. https://doi.org/10.5465/amr.2006.22527456

Lee, Y. S. (1998). University-Industry Collaboration on Technology Transfer: Views from the Ivory Tower. Policy Studies Journal, 26(1), 69-84. https://doi.org/10.1111/j.1541-0072.1998.tb01925.x

Leonard, D. (1999). Wellsprings of knowledge: building and sustaining the sources of innovation 3. Harvard Business School Press.

Newman, M. E. J. (2018). Networks Second edition. Oxford University Press.

Nonaka, I. (1994). A Dynamic Theory of Organizational Knowledge Creation. Organization Science, 5(1), $14-37$. https://doi.org/10.1287/orsc.5.1.14

Nonaka, I., \& Konno, N. (1998). The Concept of "Ba": Building a Foundation for Knowledge Creation. California Management Review, 40(3), 40-54. https://doi.org/10.2307/41165942

Perkmann, M., King, Z., \& Pavelin, S. (2011). Engaging excellence? Effects of faculty quality on university engagement with industry. Research Policy, 40(4), 539-552. https://doi.org/10.1016/j.respol.2011.01.007 
Powell, W. W., Koput, K. W., \& Smith-Doerr, L. (1996). Interorganizational Collaboration and the Locus of Innovation: Networks of Learning in Biotechnology. Administrative Science Quarterly, 41(1), 116. https://doi.org/10.2307/2393988

Pritchard, R. M. O., Pausits, A., \& Williams, J. (2016). Positioning Higher Education Institutions From Here to There. SensePublishers : Imprint : SensePublishers. https://doi.org/10.1007/978-94-6300-660-6

Racherla, P., \& Hu, C. (2010). A social network perspective of tourism research collaborations. Annals of Tourism Research, 37(4), 1012-1034. https://doi.org/10.1016/j.annals.2010.03.008

Rafiei, A., Akhavan, P., \& Hayati, S. (2016). Knowledge management in successful technology transfer (Case study: Iranian aerospace industries and knowledge-based centers). Aircraft Engineering and Aerospace Technology, 88(1), 178-188. https://doi.org/10.1108/AEAT-11-2013-0220

Schaeffer, V., Öcalan-Özel, S., \& Pénin, J. (2020). The complementarities between formal and informal channels of university-industry knowledge transfer: a longitudinal approach. The Journal of Technology Transfer, 45(1), 31-55. https://doi.org/10.1007/s10961-018-9674-4

Shannon, P. (2003). Cytoscape: A Software Environment for Integrated Models of Biomolecular Interaction Networks. Genome Research, 13(11), 2498-2504. https://doi.org/10.1101/gr.1239303

Smith, H. L., Chapman, D., Wood, P., Barnes, T., \& Romeo, S. (2014). Entrepreneurial Academics and Regional Innovation Systems: The Case of Spin-Offs from London's Universities. Environment and Planning C: Government and Policy, 32(2), 341-359. https://doi.org/10.1068/c11159b

Tsai, W. (2001). Knowledge Transfer in Intraorganizational Networks: Effects of Network Position and Absorptive Capacity on Business Unit Innovation and Performance. Academy of Management Journal, 44(5), 996-1004. https://doi.org/10.5465/3069443

Wasserman, S., \& Faust, K. (1994). Social network analysis: methods and applications. Cambridge University Press. 